\section{Economic issues on food safety}

\author{
Felice Adinolfi, ${ }^{1}$ Jorgelina Di Pasquale, ${ }^{1}$ \\ Fabian Capitanio ${ }^{2}$ \\ 'Department of Veterinary Sciences, \\ Alma Mater Studiorum-University of \\ Bologna, Ozzano Emilia (BO); \\ ${ }^{2}$ Department of Agriculture, University of \\ Naples Federico II, Portici (NA), Italy
}

\section{Abstract}

A globalised food trade, with a huge increase of the exchanged volume, extensive production and complex supply chains are contributing towards an increased number of microbiological food safety outbreaks. All of these factors are putting pressure on the stakeholders, either public or private, in terms of rule and control. In fact, this scenario could force manufacturers to be lenient towards food safety control intentionally, or unintentionally, and result in a major foodborne outbreak that causes health problems and economic loss. As a response to emerging calls for the adoption of a systemic approach to food safety, we try to identify and discuss the several related economics issue in this field. Based on an extensive analysis of academic and policy literatures on the economic effects of global environmental change at different stages of the food system, we highlight the main issues involving economists in the field of food safety. In the first part, we assessed the several approaches and problems related to the evaluation of food safety improvements, followed by an overview of drivers of food safety demand in the second part. The third section is devoted to discussing changes occurred at the institutional level in building and managing food safety policies. The last section summarises the main considerations aroused from the work.

\section{Introduction}

In the latest decade the attention on the issue of food safety has hugely increased. In Europe, as in the rest of the world, several scandals have damaged consumers' confidence in the safety of food (Valeeva et al., 2004), feeding concerns about food safety hazard and driving a growing demand for safer food (Hoffmann, 2010a; Nayga et al., 2004). Among others, Escherichia (E.) coli outbreak in the United States, bovine spongiform encephalopathy (BSE) on British beef, dioxin contamination of animal feed in Belgium, are the most relevant events registered in the recent years. Therefore, this scenario has generated the need to set out a new generation of food safety policy aimed at build a preventive and public health- focused policy, coping with foodborne hazards from farm-to-fork by strengthening integrated management along the food supply chain (Hoffmann, 2010a, $2010 \mathrm{~b})$. At the same time technological transformations are driving towards an even more globalised food system, fostering Institutions to intensify both their efforts in catching up this change (and their implication for policy maker) and also dialogues around international food legislation (De Castro et al., 2012). In fact, as a counterpart of consumers benefits resulting from the increased international food trade - in quality variety and price of food - new hazards, including previously controlled, are emerging. As the supply chain crosses national borders, risks became inevitably globalised. Therefore, whereas in the past foodborne outbreak has been characterised by concentration and intensity, nowadays they are relatively more, often affecting many countries and characterised by low-level contamination.

The transition from the previous - and first generation of food safety policy started in the early twentieth century as reaction to some scandals occurred in the food industry (Sinclair, 1906) - to the current, is driving by the switch from a food safety system regulation based on command and control forms to science-based risk management systems able to ensure more flexibility to the supply chain's actors and better targeting public efforts in the field of food safety (Hoffmann, 2010a, 2010b). This transition is far from complete and economist are called into play a crucial role in this process for several aspects such as risk assessment, food policy design, research into consumers behaviours (Hoffmann and Anekwe, 2013) and others linked to both structures and governance of food supply chain. On the demand side, safety represents one of the multiple and complex set of non-separable attributes of food (Lancaster, 1971; Chambers, 1988; Adinolfi and De Rosa, 2002) that are each other interconnected. Also on the supply side safety represents just one of the functions ensured providing food to the market (Chambers, 1988). On the supply side safety represents just one of the functions ensured providing food to the market (Chambers, 1988). This work aims to recognise the main issues involving economist on the field of food safety. An assessment of approaches and problems related to the evaluation of food safety improvements is contained in the first section, followed by an overview of drivers of food safety demand in the second one. The third section is devoted discuss changes occurred at institutional level in building and managing food safety policies. Last section summarises the main considerations aroused from the work.
Correspondence: Jorgelina Di Pasquale, Department of Veterinary Sciences, Alma Mater Studiorum-University of Bologna, via Tolara di Sopra 50, 40064 Ozzano Emilia (B0), Italy. Tel: +39.051.2097394.

E-mail: jorgelina.dipasquale@unibo.it

Key words: Food safety; Food policy; Consumer behaviours; Risk perception; Public goods.

Received for publication: 12 October 2015.

Revision received: 3 November 2015.

Accepted for publication: 3 November 2015.

This work is licensed under a Creative Commons Attribution-NonCommercial 4.0 International License (CC BY-NC 4.0).

(C) Copyright F. Adinolfi et al., 2016

Licensee PAGEPress, Italy

Italian Journal of Food Safety 2016; 5:5580

doi:10.4081/ijfs.2016.5580

\section{Valuing food safety improvement}

Starting from hazard analysis critical control point (HACCP) definition, three main sources of hazard: firstly, the unacceptable presence of a biological, chemical or physical contaminant; secondly, the unacceptable potential for growth or survival of micro-organisms or the unacceptable potential for the generation of chemicals; latest, the unacceptable contamination or recontamination with microorganisms, chemicals or foreign material. Several types of hazards may cause food-borne illnesses with different related implications in terms of public health and as recognised in recent experiences a zero-risk standard is likely to be unrealistic to reach at the moment (Unnevehr and Jensen, 1999), without tackle unbearable costs. In fact, although food-borne hazard have been studied for more than a century not all aspects has been exploited and analysed (Van Schothorst, 1999) leaving many of the known hazards a complete risk assessment is not available yet (Valeeva et al., 2004; Swanenburg et al., 2001). Moreover, changes occurring in techniques and inputs used along the food chain as well as the growing international market integration may generate unusual hazards (Swanenburg et al., 2001).

On the field of public actions the aim is to ensure higher safety standard for food product defining rules and controls aimed at reducing the incidence of food-borne illnesses (Buzby et al., 1998). From the producers' point of view the purpose is meeting food safety related standards provided by public rules - the existing acceptable hazard levels - minimising the likelihood of being a source of hazards (Ollinger and Ballenger, 2003). Despite the dif- 
ferent background, improving food safety is therefore a common objective for both Governments and producers whose are engaged in achieving higher levels of safety (Buzby et al., 1998; Hoffmann and Anewke, 2013). It is translating in several measures and actions involving the overall chain that come at cost for both (Valeeva et al., 2004; MacDonald and Crutchfield, 1996). This necessarily means that costs arising from the implementation of government regulations should be sustainable for the public system as for the other (private) actors involved in the food chain, including consumers, who should have access to food at a reasonable cost. As a consequence the role of economic evaluations in upgrading rules, actions, control instruments and governance of the food safety systems, is rapidly gaining importance. In this environment, the general objective is to identify combinations of available measures and instruments that allow improving food safety reducing risks - in the most (and viable) economic way (Kuchler and Golan, 1999; Miller et al., 2006). Followings Valeeva et al. (2004), the many approaches and methods developed to compare benefit and cost of food safety improvement by means of different commitments can be divided into three major groups: risk-risk and health-health analyses (RRA and HHA), cost-effectiveness analysis (CEA), and cost-benefit analysis (CBA).

The first group includes risk-risk and health-health analyses. Those techniques not allow users to monetise benefits and costs. RRA neither allows estimating net-benefit, given that, with rare exceptions, benefits and costs are expressed in different units (Kuchler and Golan, 1999). For example the reduced incidence of an infectious linked to a new safety measure compared whit the increasing diffusion of other causes of illness. Health-health analysis compares the number of deaths avoided implementing a certain measure with those resulting from the cost to put in play such measure (Valeeva et al., 2004). The RRA is useful only in case of problem of choosing from two alternatives status, while the HHA allow to measure net benefit in terms od reduced deaths and it is useful only in case benefit are expressed in terms of avoided deaths.

Cost-effectiveness analysis methods compare a number of physical benefits, such as averted or adverse outcomes, with monetised costs. Also in this case the different unit used in measuring benefits and costs does not permit to calculate net benefit, but CEA techniques are useful in ranking different alternatives, noting, however that they non allow comparison among action with different benefits (Kuchler and Golan, 1999). The third group of methods, CBA, aims at comparing in monetary terms both benefits and costs, allowing to calculate net benefits of interventions and comparing costs and returns for all the option available. The main difficult in applying those methods is the complexity arising from the process assigning monetary value to food safety benefits. Food safety is, in fact, a public good or non-market good (De Castro et al., 2011) and its improvements can generate direct and indirect benefits. The firsts are those to which is possible assigning a correspondent monetary value; the seconds are non-monetary and a correspondent money value can be assigned only implicitly (Belli et al., 2001; Valeeva et al., 2004). The latter group of methods is the only one which allows comparing net benefit of alternative options, thanks to both estimation techniques aimed at translates non-monetary outcomes in monetised benefits and several modelling tools for measuring compliance costs and their related impact on markets (Valeeva et al., 2004). Concerning the benefits evaluation, either cost of illness (COI) and willingness to pay (WTP) methods are the most widespread, given the nature of public good of food safety (Buzby et al., 1998). The scope of the COI approaches is assigning values to the social welfare changes, mainly assessing direct (medical) and indirect (income losses) costs in case of food-born illness (Antle, 1999, 2001; Valeeva et al., 2004). On the other hand, WTP methods are based on the role that individual preferences and estimated changes in welfare supply play to reduce risk (or the minimum compensation required for accept riskier choice) (Misra et al., 1991). Both approaches are affected by some criticism. The most relevant one for $\mathrm{COI}$ is the underestimation of social costs (Kuchler and Golan, 1999), while for WTP, although a broad range of methods developed for eliciting it, the main criticism are linked with the relevant limitation related to values assigned under hypothetical scenarios or defined through experimental markets. In valuating social costs, usually they are splitter into three groups (Unnevehr and Jensen, 1999). The real-source compliance costs consider the direct cost sustained by producers for improve food safety; the social welfare losses include variations in consumers and producers surplus arising from food safety measures and the transitional social costs refer to cost that might occur in a transitional period in case resource are removed or shifted in consequences of new/additional food safety requirement (Antle, 2001). The nature of costs considered raises a number of issues at stake. Furthermore In many cases the analysis are complicated by both the large scope and the multiple effects of measures for improve food safety.

\section{Consumer's behaviour towards food safety}

Trying to better understand consumer behaviour in food issues, basically we need to consider the consumption not as a single act but as a process, where each phase can be affected by the cultural and social context in which the individual matures purchasing decisions. Food safety issue has received wide media coverage after the above mentioned food safety crises, influencing consumption behaviours and undermines the confidence of consumers in the food industry around the world and in particular in Europe (De Castro et al., 2011). In order to regain the confidence of consumers, both the policy makers and the food industry have experienced significant changes. As a result of this re-modelling, the EU institutions have founded in 2002 the European Food Safety Agency (EFSA) and introduced numerous laws with the aim to reduce the information asymmetry among consumers and food industry. At the same time, firms have reinforced control and tracing systems in order to minimise risks along the food supply chain.

According to the Fischler's theory (1988), the omnivore's paradox, humans live their lives in constant tension and oscillation between two poles: neophilia and neophobia. On one hand, humans need variety, innovation and exploration, on the other they feel to be prudent and scared by the unknown food, because it is a potential danger. Consumers develop routines for food and eating behaviours, characterised by a decreasing effort in search (Adinolfi et al., 2011), especially for those that can be defined convenience goods. Conversely, people are affected also by an inherent desire to give discontinuity in routines purchase, introducing innovations in consumption (Bianchi, 1998). Berlyne (1971) found that the novelty, variety and surprise, would have a positive effect on pleasure that is a cognitive component affecting perception, decreasing or increasing its level of transposition. On the opposite, novelty can be perceived as source of risk, especially when food product is never been consumed or show unfamiliar characteristics (Martinez et al., 2007). In a more globalised and technological food system new products and new combination of their attributes, populate daily stores, feeding consumer's demand of information.

The expected-utility theory assumes that risk perception is an analytic procedure. People assess risk between the severity and likelihood of possible outcomes and choose by comparing their expected utility values (von Neumann and Morgenstern, 1953). An alterna- 
tive theoretical perspective is the risk-as-feelings hypothesis. In this theory, authors conceptualise the risk evaluation as an intuitive process rather than an analytic cognitive activity, highlighting the role of feelings - like concern, fear, dread, and anxiety - in risk perception (Lowenstein, et al., 2001; Slovic et al., 2004). This approach suggests that consumers prefer familiar stimuli rather than novels (Zajonc, 1980) and than that intuitive judgments and the associate emotional reaction to risky situations often diverge from analytic assessments (Schwarz, 2004). Song and Schwarz (2009) have explored in this filed the fluency which a stimulus can be processed, finding that risk perception of consumers is influenced by the fluency of the names of additives contained in food products.

Implicitly this would mean that consumers' choices are strictly affected by the sources of information (Rick and Loewenstein, 2008; Hennig-Thurau et al., 2004). Consequently, food safety can be considered as a dimension of quality (Caswell and Hooker, 1996) that would be considered as a sleeping giant. This expression provided by Grunert (2005) means that in case of food outbreaks, in the short-run food safety overcame all other food attributes in consumers' choice, while in the lung-run consumers take it in less consideration, assuming that food products sold in the market is in compliance with the food safety minimum legal requirements (Fontes et al., 2013). Emotion plays an important role also in the way consumers apply safety considerations to certain production technologies, e.g. genetically modified organism consumption (Grunert, 2005). In this case is the lake of knowledge and information to play the role of giant in the short as long as in the long run. Several studies showed the relevance of consumer risk attitudes and perceptions towards safety on food demand (Lusk and Coble, 2005) and how the use of information could contribute to shaping perceptions about food safety (Pennings et al., 2002).

In this context, food safety may be considered a credence quality attribute and consistently with its nature, standards and certifications could reduce imperfect knowledge and contribute to legitimate health and safety regulation (Fontes et al., 2013). Demand for food safety generates also incentive to private sector in adopting and communicating effort and signals in this regard. Considering food safety a credence attribute means that consumer reacts to the perceived rather than the objective risk and signals of quality became a particularly important leverage of market differentiation, especially in case of outbreak (Wezemael et al., 2010).

Consumers may access to multiple sources of information but this not necessary imply that every consumer weights in the same way or even uses the same sources. Risk behaviours are influenced by access, quality and use of information sources and by consumers trust in both risk information and the providers (Slovic, 1999). This means that reducing gap in knowledge and information is a priority in order to ensure a better market functioning and most cost-effectiveness regulatory systems. Standards fixed by public authorities, voluntary certification managed by public bodies, communication strategy adopted by producers and retails are instruments able to increase transparency on the production process. But at the same time there are concerns regarding the issues of both ethical responsibilities in communication address consumers and overlapping of messages provided by quality signal. The latter is one of the major concerns when credence attributes of a private good are associated with public good characteristics, such as food safety, animal welfare, and environmental sustainability. In many cases in fact certification of certain aspects of food process - social or environmental - are perceived as linked with food safety (Fontes et al., 2013). In others the amounts of information and signals generates confusion and misunderstandings in consumers (Di Pasquale et al., 2014). These circumstances affect negatively the efforts in reducing the gap in consumer's knowledge and information and in some case the jointly communication of different credence attributes to the consumer can exacerbate the problem.

\section{Food safety and international trade rules}

The rising integration along the supply chain and between markets is feeding by the expansion of the middle class around the world and facilitated by the reduction of technical and trade barriers (Gelhar and Regmi, 2005). This introduces concerns about food safety shared across national borders as the evolution of food system is leading by a deep integration in production, retail and consumption around the world (Birdsall and Lawrence, 1999). In this regard food safety can be considered as a global public good (Unnevehr, 2006) that is characterised by the fact that externalities (positive or negative) cross the border and benefits providing utility are in principle available on international ground (Ferroni and Mody, 2002). Institutional innovation are emerging in order to adapt public and private standards, regulations and behaviour to the growing globalisation of food safety risks (Unnevehr, 2006). There are widely recognised private standards (Gelhar and Regmi, 2005); efforts provided by foreign assistance in developing countries in order to improve struc- tures and institutional capacity devoted to food safety; international agreement aimed at improving compliance at global level.

Access to international market may generate additional costs for producers in order to address and managing food safety standards. Differences in national systems are frequently viewed as technical barriers to trade, especially when they regards trade between developed countries. The general agreement on trade and tariffs (GATT) provide the legal structure for international trade and recognise exceptions to its general requirements. On of the most relevant is that regarding action to protect health. As a part of the GATT, sanitary and phytosanitary (SPS) agreement adopted by World Trade Organization (WT0) members, providing rules about national sanitary and phytosanitary laws comply with GATT (under the SPS agreement, standards consistent with those agreed to by the Codex Alimentarius Commission are presumed to be in compliance with GATT; nations adopting other standards need to support their scientific legitimacy through risk analysis) and a framework for addressing disputes regarding these measures. Under SPS agreement WTO shared three main principles (Buzby et al., 1998): transparency: member nations are required to publish their regulations and provide a mechanism for answering questions from trading partners; equivalence: member nations must accept that SPS measures of another country are equivalent if they result in the same level of health protection; science-based measures: SPS measures must be based upon risk assessments and must be based upon risk assessments and must be chosen so as to minimise distortions to trade; harmonisation: member nations recognise the desirability of common SPS measures. The Codex Alimentarius Commission (Codex) for human health measures, the International Office of Epizootics for animal and human health measures, and the International Plant Protection Convention for plant health measures are the three international organisations are recognised as sources of internationally agreed-upon standards.

Even if the Codex has facilitated international discussion about common standards and the SPS agreement has helped international negotiations about the adoption of new food safety standards on area of growing controversy remain the difference existing among countries in risk assessment procedures as well in emergency measures adopted in case of risk of food break.

\section{Conclusions}

Economists are called to play a crucial work in the improvement and harmonisation of food 
safety measures. This paper provides an overview of the three main axes on which this work should be implemented, emphasising the major problems that economists have to face in the near future. Food safety itself is rather complex (Valeeva et al., 2004) and its nature poses problems about related indicators and measures. With regard to the consequences resulting from the implementation of new food safety action, although considerable progress has been made evaluating benefits and costs associated to food safety improvement, some issues are still poorly explored. Researches have been mostly concentrated on the consumer's side, while producer's benefit evaluations have been neglected.

Nowadays, safety is a non-negotiable attribute of food in developed countries and its relevance is strongly influenced by information asymmetry that characterises market. Therefore, amplification of the risk or media coverage can greatly influence consumers' behaviour (Fontes et al., 2013). The role played by source of information is fundamental in addressing market failures, starting from avoiding confusion in information provided to consumers aroused from the proliferation of public and private signals of quality.

Finally, food safety initiatives are even more interlinked at the global level. As the food system has become more globalised, hazards are shared across the borders. International rules on trade have contributed to harmonise national systems but the number of past and on-going disputes over the SPS agreement reveals that many steps forwards are still to be made.

\section{References}

Adinolfi F, De Rosa M, 2002. L'effetto della novità sui comportamenti di consumo: considerazioni teoriche e verifiche empiriche sui prodotti alimentari. Riv Econ Agr 4:733-58.

Adinolfi F, De Rosa M, Trabalzi F, 2011. Dedicated and generic marketing strategies: the disconnection between geographical indications and consumer behaviour in Italy. Brit Food J 113:419-35.

Antle JM, 1999. Benefits and costs of food safety regulation. Food Policy 24:605-23.

Antle JM, 2001. Economic analysis of food safety. In Gardner B, Rausser G, eds. Handbook of agricultural economics. Elsevier Science, Amsterdam, The Netherlands, pp 1083-136.

Belli P, Anderson JR, Barnum HN, Dixon JA, Tan JP, 2001. Economic evaluation of health projects. World Bank, Washington, DC, USA.

Berlyne DE, 1971. Aesthetics and psychobiolo- gy. Appleton Century Crafts, New York, NY, USA.

Bianchi M, 1998. Consuming novelty: strategies for producing novelty in consumption. J Mediev Early Mod S 28:3-18.

Birdsall N, Lawrence RZ, 1999. Deep integration and trade agreements. In: Kaul I, Grunberg I, Stern MA, eds. Global public goods. International cooperation in the 21st century. Oxford/New York, UK/USA, pp 128-51.

Buzby JC, Fox JA, Ready RC, Crutchfield SR, 1998. Measuring consumer benefits of food safety risk reductions. J Agr Appl Econ 30:69-82.

Caswell JA, Hooker NH, 1996. HACCP as an international trade standard. Am J Agr Econ 775-9.

Chambers RG, 1988. Applied production analysis: a dual approach. Cambridge University Press, Cambridge, UK.

De Castro P, Adinolfi F, Capitanio F, Di Falco S, 2011. Building a new framework for the CAP: a responsibility towards the overall community. Eurochoices 10:32-6.

De Castro P, Adinolfi F, Capitanio F, Di Pasquale J, 2012. The future of European agricultural policy. Some reflections in the light of the proposals put forward by the EU Commission. New Medit 2:4-11.

Di Pasquale J, Nannoni E, Del Duca I, Adinolfi F, Capitanio F, Sardi L, Vitali M, Martelli G, 2014. What foods are identified as animal friendly by Italian consumers? Ital J Anim Sci 13:782-9.

Ferroni MA, Mody A, 2002. International public goods: incentives, measurement, and financing. Available from: http://documents.worldbank.org/curated/en/2002/03/2 014506/international-public-goods-incentives-measurement-financing

Fischler C, 1988. Food, self and identity. Soc Sc Inform 27:275-93.

Fontes MA, Giraud-Heraud E, Seabra Pinto A, 2013. Consumers' behavior towards food safety: a literature review. Ecole Polytechnique, Centre National de la Recherche Scientifique, Paris, France.

Gelhar M, Regmi A, 2005. New directions in global food markets. Available from: www.ers.usda.gov/media/872111/aib794_0 02.pdf

Grunert KG, 2005. Food quality and safety: consumer perception and demand. Eur Rev Agric Econ 32:369-91.

Hennig-Thurau T, Gwinner KP, Walsh G, Gremler DD, 2004. Electronic word-ofmouth via consumer-opinion platforms: what motivates consumers to articulate themselves on the internet? J Interact Mark 18:38-52.

Hoffmann S, 2010a. Ensuring food safety around the globe: the many roles of risk analysis from risk ranking to microbial risk assessment: introduction to special series. Risk Anal 30:711-4.

Hoffmann S, 2010b. Food safety policy and economics: a review of the literature. Available from: www.rff.org/files/sharepoint/WorkImages/ Download/RFF-DP-10-36.pdf

Hoffmann S, Anekwe T, 2013. Making sense of recent cost-of-foodborne-illness estimates. United States Department of Agriculture, Washington, DC, USA.

Kuchler F, Golan EH, 1999. Assigning values to life: comparing methods for valuing health risks. United States Department of Agriculture, Washington, DC, USA.

Lancaster K, 1971. Consumer demand: a new approach. Columbia University Press, New York, NY, USA.

Loewenstein GF, Weber EU, Hsee CK, Welch N, 2001. Risk as feelings. Psychol Bull 127:267-86

Lusk JL, Coble KH, 2005. Risk perceptions, risk preference, and acceptance of risky food. Am J Agr Econ 87:393-405.

MacDonald JM, Crutchfield SR, 1996. Modelling the costs of food safety regulation. Am J Agr Econ 78:1285-90.

Martinez MG, Fearne A, Caswell JA, Henson S, 2007. Co-regulation as a possible model for food safety governance: opportunities for public-private partnerships. Food Policy 32:299-314.

Miller W, Robinson LA, Lawrence RS, 2006. Valuing health for regulatory cost-effectiveness analysis. National Academies Press, Washington, DC, USA.

Misra SM, Huang CL, Ott SL, 1991. Consumer willingness to pay for pesticide-free fresh produce. Western J Agr Econ 16:218-27.

Nayga RM, Poghosyan A, Nichols JP, 2004. Will consumers accept irradiated food products? Int J Consum Stud 28:178-85.

Ollinger ME, Ballenger N, 2003. Weighing incentives for food safety in meat and poultry. Available from: http://www.ers.usda.gov/amberwaves/2003-april/weighing-incentives-forf $00 \mathrm{~d}-\mathrm{s}$ a f e t y - in - m e a t - a n d poultry.aspx\#.VvPn3z8o0yp

Pennings JME, Wansink B, Meulenberg MTG, 2002. A note on modeling consumer reactions to a crisis: the case of the mad cow disease. Int J Res Mark 19:91-100.

Rick S, Loewenstein G, 2008. Intangibility in intertemporal choice. Philos T R Soc B 363:3813-24.

Schwarz N, 2004. Meta-cognitive experiences in consumer judgment and decision making. J Consum Psychol 14:332-48.

Sinclair U, 1906. The jungle. Doubleday, Jabber and Company, New York, NY, USA.

Slovic P, 1999. Trust, emotion, sex, politics, and science: surveying the risk-assessment battlefield. Risk Anal 19.4:689-701. 
Slovic P, Finucane ML, Peters E, MacGregor DG, 2004. Risk as analysis and risk as feelings: some thoughts about affect, reason, risk, and rationality. Risk Anal 24:311-22.

Song H, Schwarz N, 2009. If it's difficult to pronounce, it must be risky. Fluency, familiarity, and risk perception. Psychol Sci 20:135-8

Swanenburg M, Rijsman VMC, Teeuw J, Mengelers MJB, Noordam MY, SchwarzBovee A, 2001. A framework for defining hazard indicators in the food supply chain. Agricultural Economics Research Institute, Wageningen, The Netherlands.

Unnevehr LJ, 2006. Food safety as a global pub- lic good: is there underinvestment? Available from: ageconsearch.umn.edu /bitstream/25733/1/pl06un01.pdf

Unnevehr LJ, Jensen HH, 1999. The economic implications of using HACCP as a food safety regulatory standard. Food Policy 24:625-35.

Valeeva NI, Meuwissen MPM, Huirne RBM, 2004. Economics of food safety in chains: review of general principles. Neth $\mathrm{J}$ Agr Sci 51:369-90.

Van Schothorst M, 1999. Microbiological and hygienic aspects of food safety. In: Van Der Heiden K, Younes M, Fishebein L, Miller S, eds. International food safety handbook: science, internantional regulation, and control. Marcel Dekker, New York, NY, USA, pp 27-46.

Von Neumann J, Morgenstern 0, 1953. Theory of games and economic behavior. Princeton University Press, Princeton, NJ, USA.

Wezemael LV, Verbeke W, Kugler J0, de Barcellos MD, Grunert KG, 2010. European consumers and beef safety: perceptions, expectations and uncertainty reduction strategies. Food Control 21:835-44.

Zajonc RB, 1980. Feeling and thinking: preferences need no inference. Am Psychol 35:151-75. 